\title{
Customizing Functional Rehabilitation and Return to Sport in the Female Overhead Athlete
}

\author{
Stephanie L. Boudreau, P.T., D.P.T., Laura L. Mattes, P.T., D.P.T., O.C.S., \\ Natalie A. Lowenstein, B.S., Elizabeth G. Matzkin, M.D., and \\ Reg B. Wilcox III, P.T., D.P.T., M.S., O.C.S.
}

\begin{abstract}
Participation of female athletes in sports at all levels continues to grow exponentially, as well as the injuries they experience during play. A literature review does outline return to sport guidelines, yet few studies address the potential need for differences between male and female athletes. This commentary is a review of the literature that outlines various sports that involve both male and female overhead athletes and potential differences in upper-extremity injuries and strengths and weaknesses between sexes. This information proposes the potential need to customize returnto-sport guidelines and screens that include recommendations for overhead female athletes within their specific sport, following both injury as well as surgical intervention. Level of Evidence: V.
\end{abstract}

$\mathbf{M}$ ost understand that an overhead athlete participates in any sport or activity where the upper arm and shoulder arcs overhead routinely throughout the sport's activity. Baseball, cricket, tennis, volleyball, and throwing events in track and field are widely accepted as overhead sports. In addition, many portions of other sports, like lacrosse, golf, soccer, gymnastics, and basketball, incorporate overhead movements. Overhead sports injuries can be multifactorial, leading to a range of motion deficits, muscular imbalances, scapular dyskinesis, and pain. Typically, the best prevention for overhead injuries is appropriately paced and structured sport-specific training. When an injury does occur, it is recommended that the overhead athlete seek guidance and advice from sports medicine professionals who can assess the injury and guide the intervention,

From the Departments of Rehabilitation Services (S.L.B., L.L.M., R.B.W.) and Orthopedics (N.A.L., E.G.M.), Mass General Brigham Sports Medicine, Brigham and Women's Hospital, Boston, Massachusetts, U.S.A.

The authors report that they have no conflicts of interest in the authorship and publication of this article. Full ICMJE author disclosure forms are available for this article online, as supplementary material.

Received August 3, 2021; accepted September 13, 2021.

Address correspondence to Elizabeth G.Matzkin, M.D., Department of Orthopedics, Mass General Brigham Sports Medicine, Brigham and Women's Hospital, Brigham and Women's/Mass General Health Care Center, 20 Patriot Place, Foxboro, MA 02135.E-mail: ematzkin@bwh.harvard.edu

(C) 2021 THE AUTHORS. Published by Elsevier Inc. on behalf of the Arthroscopy Association of North America. This is an open access article under the CC BY-NC-ND license (http://creativecommons.org/licenses/by-nc-nd/4.0/).

2666-061X/211120

https://doi.org/10.1016/j.asmr.2021.09.041 rehabilitation, and return-to-sports plan to optimize recovery. An appropriate return-to-sports plan should be completed either following conservative care for an injury or following postoperative rehabilitation for those that have required surgical intervention.

Every overhead athlete is not the same. Many things need to be considered when setting the rehabilitation and return-to-sport program for an overhead athlete. Mechanism of injury and previous frequency of injury are essential to understand. The body composition, sex, and desired overhead sport the athlete wants to return to are critically important parameters one needs to consider during the rehabilitation and return to sport program. Ensuring proper readiness for overhead activities is vital for any sports medicine clinician to determine before advising an overhead athlete to begin a sports-specific training program in advance of return to play. This article will highlight key components of functional assessment to determine readiness for sportspecific training, review critical differences between overhead sports, and identify critical sex-specific considerations that need to be considered during the rehabilitation process to customize return to sport guidelines.

\section{Sex and Age Considerations}

A cross-sectional study by Chimera et al. ${ }^{1}$ looked at 2 outcome measures, the Functional movement system (FMS) and Y balance test (YBT), among male and female Division I athletes to assess any differences among the sexes with scoring (Fig 1). The study concluded that 
male and female athletes scored similarly in dynamic balance measures yet differently among movement patterns. Female athletes scored worse than male athletes with movement patterns involving core strength yet better with movement patterns involving flexibility and balance. This was also seen with recreational sports. ${ }^{1}$ This information may assist in modifying established return-to-sport guidelines in adding areas to focus on specific core strength needs as they pertain to specific sports for female athletes and flexibility and balance components for male athletes. (Appendix Table 1, available at www.arthroscopyjournal.org).

Joint flexibility, altered alignment (Q-angles, cubital angles), and hormonal influences also are cited as intrinsic differences between male and female athletes, affecting injury rates. ${ }^{2}$ Much of the research into hormones, flexibility, and injury rates are related to the lower-extremities, such as anterior cruciate ligament injuries ${ }^{3}$; however, basic principles could be applied to other joints such as the shoulder and elbow. There is some evidence that oral contraceptives may offer a reduction in injury risk; however, there is no consensus and further research is warranted. ${ }^{4}$ Some initial research suggests that men and women use different motor control patterns, with men having better acuity regarding their joint position. ${ }^{5}$ This could lend itself to ensuring that proprioception plays a more significant role in rehabilitating overhead female athletes.

Another factor that will affect an athlete's recovery from injury or surgery and their return to sport is a past or present history of low energy availability, the main component of Relative Energy Deficiency in Sport (RED-S) - essentially defined as not taking in enough energy or over-expenditure of energy resulting in reduced physical regulation and performance. ${ }^{6}$ It is well known that RED-S is associated with metabolic, endocrine, menstrual function, and bone health effects. The total prevalence is reportedly $22 \%$ to $58 \%$ of male and female athletes, with cycling and elite distance athletes having some of the greatest incidences. ${ }^{7}$ The female athlete triad includes low energy availability, menstrual dysfunction, and low bone mineral density. ${ }^{8,9}$ It has been reported that the rate of amenorrhea has been reported as high at $60 \%$ of elite middle- and longdistance athletes and $23 \%$ among elite sprinters. ${ }^{10}$ Bone stress/overuse injuries are one of the most common injuries associated with the triad/RED-S, although more frequently in the lower extremity. Gymnastics is known to be harder on the upper extremities due to the increased weight-bearing. In young gymnasts, wrist pain prevalence ranged between $32 \%$ and $73 \%$ and overuse wrist injury rates were $10 \%$ to $28 \% .{ }^{11}$ The concepts from research on lower-extremity bone stress injuries can be applied to the upper extremities, and more research directed at upper extremities is warranted. Being aware of the Triad/RED-S is important in the care of female athletes in order to prevent further injury and to recover most effectively from injury/surgery and return to sports.

Typical age-related changes for both male and female subjects include increasing osteoporosis and physiological changes such as decreased lean body mass and strength. Rehabilitation for a master's athlete will require awareness that their tendons and soft tissues will likely contain less water, increased collagen crosslinking, and be less flexible. ${ }^{12,13}$ This is also essential to assess for a history of the triad/RED-S in the female athlete, as expected decreases in bone density could be exacerbated. ${ }^{14}$ There is some evidence that as women age, their rapid vasodilatory response is decreased compared with men their age and both younger men and women. ${ }^{15}$ This could affect their ability to regain strength after an injury/surgical intervention.

\section{Specific Sports}

A review of the literature looking at various competitive sports and specific injuries associated with a particular sport did yield information that may assist in amending the return-to-sport guidelines regarding male and female overhead athletes. Chimera et al. ${ }^{1}$ reported that $20 \%$ of sports-related injuries are incurred with noncontact sports, and $40 \%$ occur during practices. These impressive percentages may warrant a need to involve more preseason screening of all players to address the risk of injuries before they occur. Various studies have looked at different screening tools like the FMS and Y Balance Test-Upper Quarter (YBT-UQ) to identify abnormal movement patterns and dynamic balance issues. ${ }^{1,16,17}$ Chimera et al. ${ }^{1}$ did demonstrate that female athletes scored better than male athletes on the FMS with movement patterns that involved flexibility and balance yet did score lower than male athletes with movement patterns that looked at overall core strength. In another study, the authors demonstrated that secondary school female athletes showed overall lower FMS scores than male athletes. ${ }^{16}$ This information may further assist coaches and conditioning professionals to customize aspects of their pre-, mid-, and postseason screening and training depending on their sport's specific demands and differences in conditioning male and female overhead athletes.

Studies by Nelson et al. ${ }^{18}$ and $\mathrm{O}^{\prime}$ Connor et al. ${ }^{19}$ reported similarly that overhead female athletes had a greater percentage of shoulder and upper arm injuries than male athletes and required surgical intervention in these areas more often than male athletes in tennis and rock climbing specifically. In addition, Butler et al. ${ }^{20}$ found that female swimmers scored worse than male swimmers in the YBT-UQ screen and consequently had a greater rate of upper quarter injuries when compared with male swimmers. This information may warrant more attention to training guidelines specifically 
A
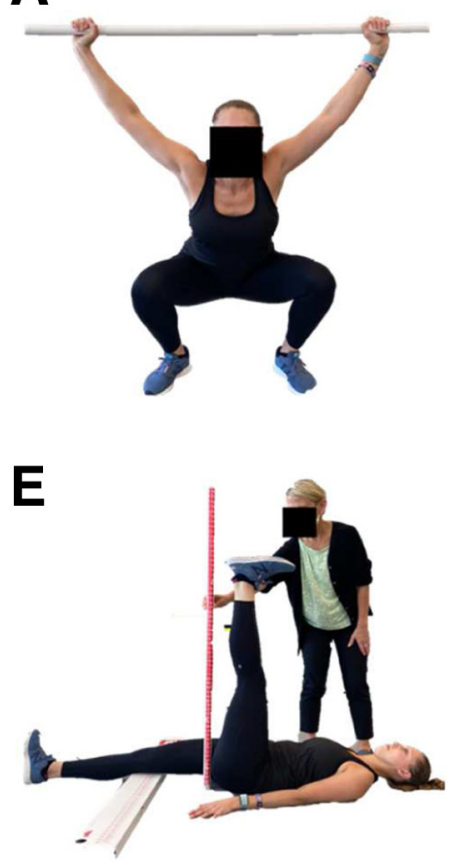

B

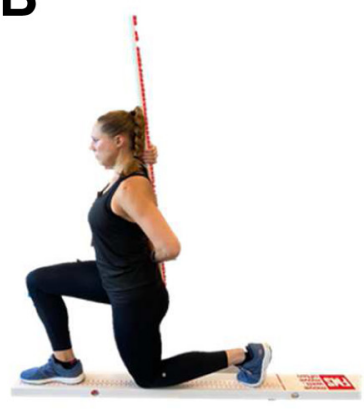

$\mathbf{F}$
C

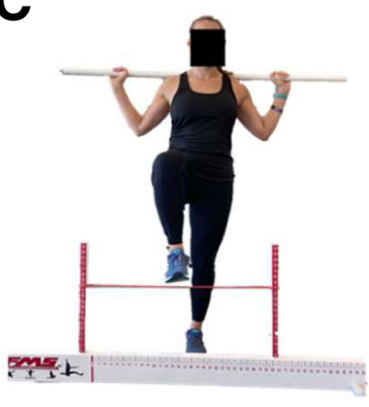

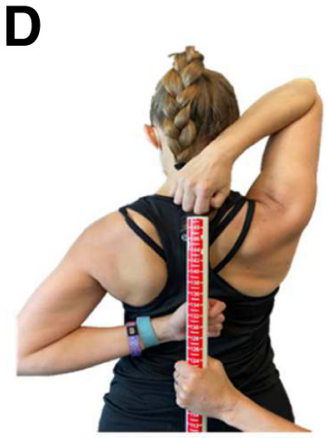

\section{G}

Fig 1. Functional Movement System (FMS): Seven test positions/activities of the FMS. (A) Deep squat. (B) In-line lunge. (C) Hurdle step. (D) Shoulder mobility. (E) Active straight-leg raise. (F) Trunk stability pushup. (G) Rotary stability.

focused on the strength of the upper quarter for female overhead athletes.

Shih and Wang ${ }^{21}$ reported that a high percentage of injuries are linked with the spiking maneuver in volleyball. They reported that $80 \%$ of shoulder injuries alone were related to spiking. The authors discussed that the shoulder joint's altered biomechanics is what appears to lead to the injuries, including poor scapula mechanics and the general nature of overuse in play. ${ }^{21}$ This finding is consistent with finding the by Vincent et al. ${ }^{22}$ among lacrosse players. Although the study did not look specifically at differences between male and female overhead athletes, we may extrapolate the greater incidence of injuries in the upper quarter with female overhead athletes. More attention to this area should be addressed with all training regiments.

As mentioned previously, Vincent et al. ${ }^{22}$ focused on, among other things, overuse injuries associated with lacrosse players. The authors reported female injuries were greater than male injuries in the arm, shoulder, and face and were more from noncontact and overuse in the sport. ${ }^{17}$ Female athletes also had a greater need for surgical intervention than male athletes. ${ }^{22}$ These findings align with study by Chimera et al. ${ }^{1}$ that looked at the high percentage of injuries that come from noncontact and practice sessions.

Two other studies, by Myers et al. ${ }^{23}$ and $\mathrm{O}^{\prime}$ Connor et al., ${ }^{19}$ looked at elite and junior tennis players. Myers et al. ${ }^{23}$ reported that male competitors hit 2 times more serves per set than female players. This finding may warrant the need to regulate serve percentage counts as commonly seen in baseball pitchers to avoid overuse and poor mechanic injuries. $\mathrm{O}^{\prime}$ Connor et al. ${ }^{19}$ looked at junior tennis players and found that female players had a greater percentage of shoulder injuries than male junior competitors. This again is consistent with the literature demonstrating the potential need to increase attention to female overhead athletes' return to play and pre-, mid-, and postseason training screens and guidelines emphasizing upper quarter strengthening.

Compared with all the aforementioned articles, one constant is consistent among athletic females: a greater incidence of shoulder and upper quarter injuries than male overhead athletes. We also have found that in addition to shoulder injuries, female compared to male athletes also have a greater overuse injury rate. Chimera et al. ${ }^{1}$ demonstrated that female athletes scored higher with flexibility components on the FMS screen yet overall were weaker in the upper quarter than males. We may be able to extrapolate that flexibility without proper strengthening may lead to abnormal movement patterns and ultimately lead to injury. This may demonstrate the need to addend treatment guidelines to focus on stabilization types of strengthening specific to overhead female athletes.

\section{Return to Play}

Functional rehabilitation should reintroduce and reproduce the positions and forces that will occur during the sport to which the athlete is returning. Despite a 


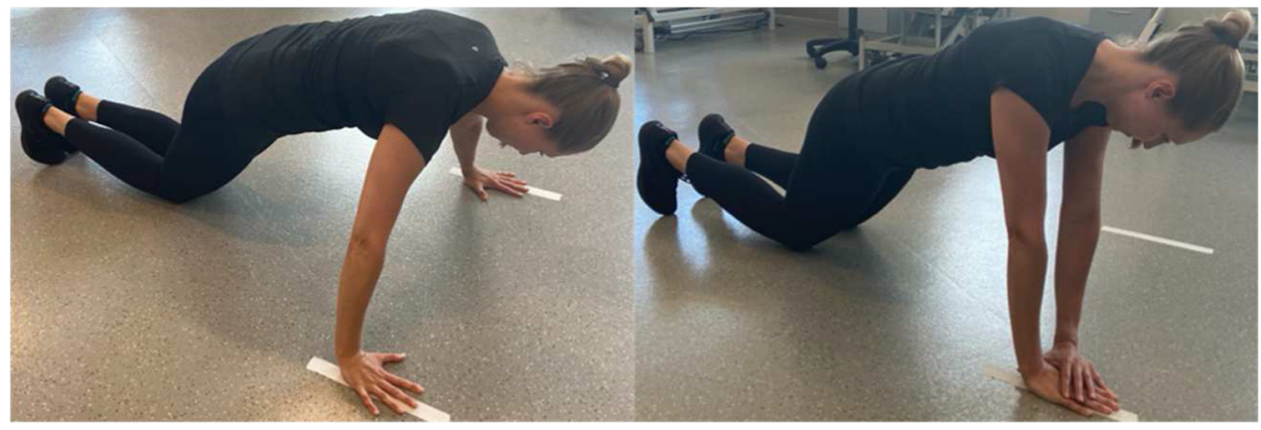

Fig 2. The Closed Kinetic Chain Upper Extremity Stability Test measures speed, agility, and/or power but requires upper quarter stability to perform without symptoms.

lack of consensus and specific recommendations, there is agreement that before being allowed to return to sport, athletes should be pain-free and demonstrate symmetric rotator cuff and bilateral scapular muscular performance, with a functional range of motion that allows sport-specific participation. These criteria should be achieved either following conservative care for an injury or following postoperative rehabilitation. Healing timelines following surgical intervention also should be taken into consideration for the patient who has undergone surgical intervention. Close collaboration between the rehabilitation professional, athlete, and surgeon is crucial for setting expectations during the transition from traditional postoperative rehabilitation to return-to-sport training and eventual return to sport activity. Sport-specific functional rehabilitation and training should emphasize restoring the injured athlete's sport-specific physiology and biomechanics to ensure optimal tolerance and performance for the sport's demands.

Return to play is commonly defined as determining when an injured athlete can safely return to sportspecific training and then competition. The timing considerations of return to sport-specific training and competition need to be sensible to ensure the rate of return is based on the severity of the original injury, rate of rehabilitation progress, re-establishment of an adequate range of motion, muscular performance, balance, and proprioception, as well as an assessment of the demands of the athlete's desired sport to return to.

\section{Functional Testing and Training}

The acceptable range of motion, resolved pain, normalized muscle performance, and an athlete's desire to return to sport-specific training are insufficient to ensure they are ready. It is recommended that the overhead athlete completes appropriate functional and sport-specific upper-extremity tests and screens to ensure readiness to return to overhead sports. Comparing an athlete's performance on such tests with evidence-based norms, the uninjured limb, and quality of form and fatigability during testing can go a long way in assisting the clinician in returning to sports training and play decisions. The Closed Kinetic Chain Upper Extremity Test (CKCUEST), the Upper Quarter Y Balance Test (UQYBT), the Seated Medicine Ball Throw Test (SMBT), the Push Up test, and the Modified Pull Up test use various setup positions, adjustments, or calculate results based on body measurements to be more athletespecific. Some, such as the CKCUEST and the SMBT, also have norms based on sex and/or sex and sport.

\section{Closed Kinetic Chain Upper Extremity Stability Test}

Th CKCUEST test ${ }^{24}$ measures speed, agility, and/or power but requires upper quarter stability to perform without symptoms (Fig 2). The clinician is looking to see how many touches the athlete can make in 15 seconds. In addition to the total touches, this test provides an opportunity to observe qualitative differences in shoulder kinematics, movement patterns, trunk activity, and the athlete's ability to assume the starting position. Common dysfunctions may include noticeable apprehension or difference inability to accept weight on the injured upper extremity compared with noninjured, scapular dyskinesis, or decreased and compensatory hip and trunk control. There are published normative data based on age groups, sports, underlying shoulder conditions, and activity level. Female athletes generally had more touches in the given testing time than male athletes. ${ }^{24-26}$ Reproducibility, validity, and responsiveness have not been established. One should exercise caution in the interpretation of the CKCUEST in relationship to risk assessment. It should not be used as a standalone tool for upper extremity sports-related injury. ${ }^{26}$

\section{Materials}

- Tape (athletic or another easily visible tape)

- Clock or timer

\section{Testing Procedure}

- Place 2 strips of tape parallel to each other 36 inches apart on the floor. However, when completing this test with female athletes, a 36-inch-wide may not be 


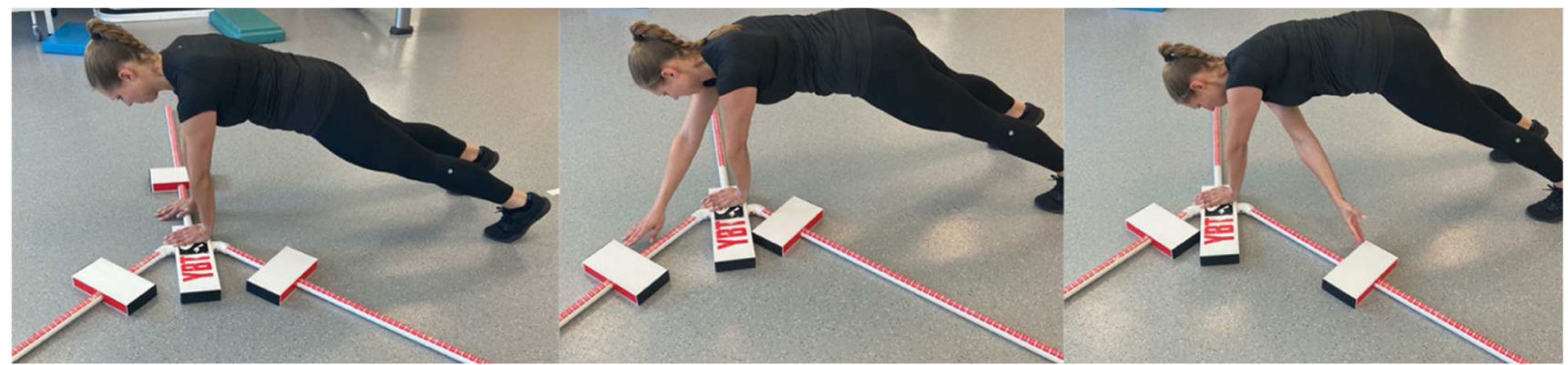

Fig 3. The Upper Quarter Y-Balance Test is a closed kinetic chain assessment of upper extremity mobility, stability, and proprioception.

reasonable, given the size of the female athlete. Narrowing this distance to fit one's body composition is suggested.

- Starting position is one hand on each piece of tape in a pushup position or a modified pushup position with knees and toes on the floor.

- The athlete will then rapidly touch the opposite hand or touch tape under the opposite hand.

- After touching, the hand is returned to its original starting position. The athlete then performs the same movement with the opposite hand.

- The total time for the trial is 15 seconds. Record total number of touches completed in 15 seconds.

- The athlete performs a warmup trial and then 3 test trials with a rest period of 45 seconds between trials. An average of 3 trials is used for test score.

- *Females are scored based on a modified pushup position

\section{Measurements}

- Touches are counted each time the hand touches the opposing hand or tape

- Power score can be calculated by: (average \# of touches $\times 68 \%$ of body weight in $\mathrm{kg}$ )/ 15 seconds

\section{Upper Quarter Y Balance Test}

The UQYBT ${ }^{27}$ is a closed kinetic chain assessment of upper extremity mobility, stability, and proprioception (Fig 3). It places an athlete in a closed-chain pushup type position. It tests their ability to maintain that position while reaching with one hand in 3 test directions of medial reach, inferolateral reach, and superolateral reach as far as possible during the entirety of the movements. This test can assist sports medicine professionals in identifying movement limitations and asymmetries, which should then be addressed to reduce injury. Clinicians should expect a rehabilitating athlete to have relative symmetry from side to side on this test before clearing them to return to sports. Clinicians should be assessing the quality of scapular movement throughout this test. Normative data exist for recreational fitness subjects and the general population, whereas sport-specific data evolves. ${ }^{17,28}$ It has been shown that there are no significant differences in performance between sexes or between sides on the test when normalized to limb length. ${ }^{29}$

\section{Materials}

- Tape (athletic or another easily visible tape)

- Tape measure

- Blocks (foam, wooden, or other lightweight blocks that are easy to slide on the given surface)

\section{Testing Procedure}

- At least 1-m long, 3 cloth measuring tapes will be placed on the ground at the same starting position, forming one $90^{\circ}$ angle and two $135^{\circ}$ angles. The tape should be marked to indicate centimeters.

- A lightweight block is placed along with each piece of tape near the origin of the tape.

- Starting position is in the pushup position, feet shoulder-width apart, with the athlete positioned so that the tape is lined up medially, superolateral, and inferolateral relative to the athlete's supporting upper extremity.

- The athlete pushes the blocks along the tape (medially, superolateral, and inferolateral) with their fingertips, without the reaching arm touching the ground until after reaching in all 3 directions

- If the athlete touches the ground before reaching all 3 directions, measurements are discarded, and the trial is repeated until 3 successful trials are obtained.

\section{Measurements}

- The average from the 3 trials for each direction is calculated

- A composite score for the total excursion is calculated by taking the sum of the 3 averages and dividing it by the athlete's upper limb length multiplied by 3 . This is then multiplied by 100 for the composite score.

- Upper limb length is measured from the C7 vertebra to the athlete's fingertips, shoulder at $90^{\circ}$ of abduction. 


\section{Seated Medicine Ball Throw Test}

The Seated Medicine Ball Throw Test (SMBT) ${ }^{30}$ measures unilateral upper-extremity power (Fig 4). Side-to-side differences in performance are usually slight in uninjured athletes. In addition to the distance measure, this test provides an opportunity to observe qualitative differences in shoulder kinematics, movement patterns, trunk activity, and the athlete's ability to assume the starting position. The difference between the dominant and nondominant sides in athletes is generally $5 \%$ to $10 \%$. Various distances have been reported based on sport in rank order from shortest to longest women's volleyball, lacrosse, softball, and basketball all trailed behind men's basketball and baseball. It has been reported that the SMBT is an inexpensive, safe, and repeatable measure of upper body power for older athletes. ${ }^{31}$

\section{Materials}

- 6-lb medicine ball

- Tape (athletic or another easily visible tape)

\section{Testing Procedure}

- The athlete sits back against a wall, next to a doorway, to allow the test arm to move freely without touching the wall. Legs are bent with feet flat on the floor.

- Place two parallel strips of tape 36" apart on the floor before the athlete forms a track to guide the throws.

- The athlete holds a 6-lb medicine ball at shoulder height on the test side.

- The athlete is instructed to push (rather than throw) the ball as far forward as possible while:

- Keeping head, back, and contralateral shoulder blade in contact with the wall.

- Keeping contralateral arm relaxed in the lap

- Encourage to facilitate the maximal effort.

- The athlete performs 2 practice trials: one at $75 \%$ of maximal effort and one at $100 \%$ maximal effort. 20 to 30 seconds of rest between each trial.

- Perform 3 maximal effort trials.

\section{Measurements}

- Record distance from the wall to the point where the ball first contacted the floor in centimeters.

- Calculate the average distance from 3 maximal effort trials.

Borms and Cools ${ }^{17}$ aimed to provide age, sex, and sport-based normative database for 3 previously covered functional shoulder tests: YBTQ, CKCUEST, and SMBT. In addition, they aimed to discuss sex, age, and sports differences. Overhead athletes between 18 and 50 years old and participating in volleyball, tennis, and handball performed all 3 functional tests. Results demonstrated significant sex and age differences for all tests. CKCUEST was moderately correlated with SMBT and YBTUQ. A weak correlation was found between SMBT and YBTUQ. In conclusion, the authors found these tests to be clinically relevant for functionally screening overhead athletes and established some benchmarks for performance based on sex, age, and sports. A combination of these tests is recommended when assessing overhead athletes.

\section{Throwing Athletes}

\section{Functional Throwing Performance Index}

The Functional Throwing Performance Index (FTPI) ${ }^{32}$ measures the accuracy of overhand-throwing athletes (Fig 5). The FTP is calculated by taking the number of accurate throws divided by the number of total throws. Throwing mechanics should be observed explicitly during this test to pick up on any aberrant movements. Clinicians should also note any shoulder irritability during the test and how long it takes to recover from that pain. Published norms inform us that males are typically about $47 \%$ accurate with a range from $33 \%$ to

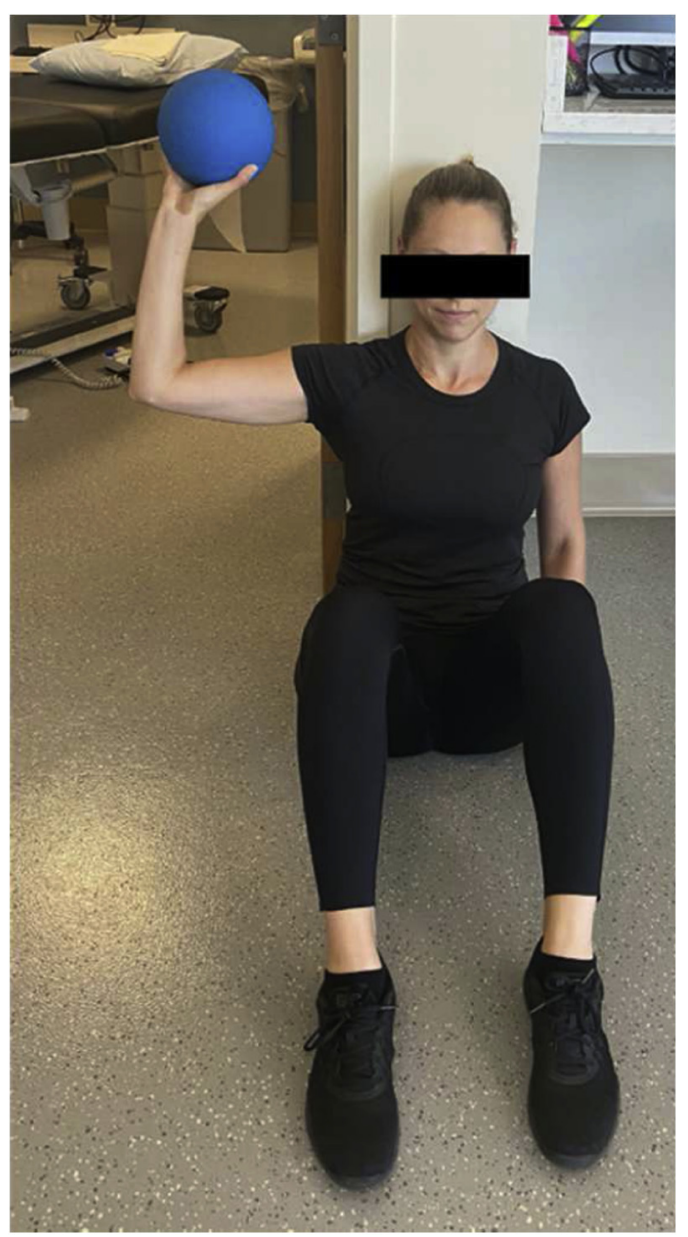

Fig 4. The Seated Medicine Ball Throw Test measures unilateral upper-extremity power. 


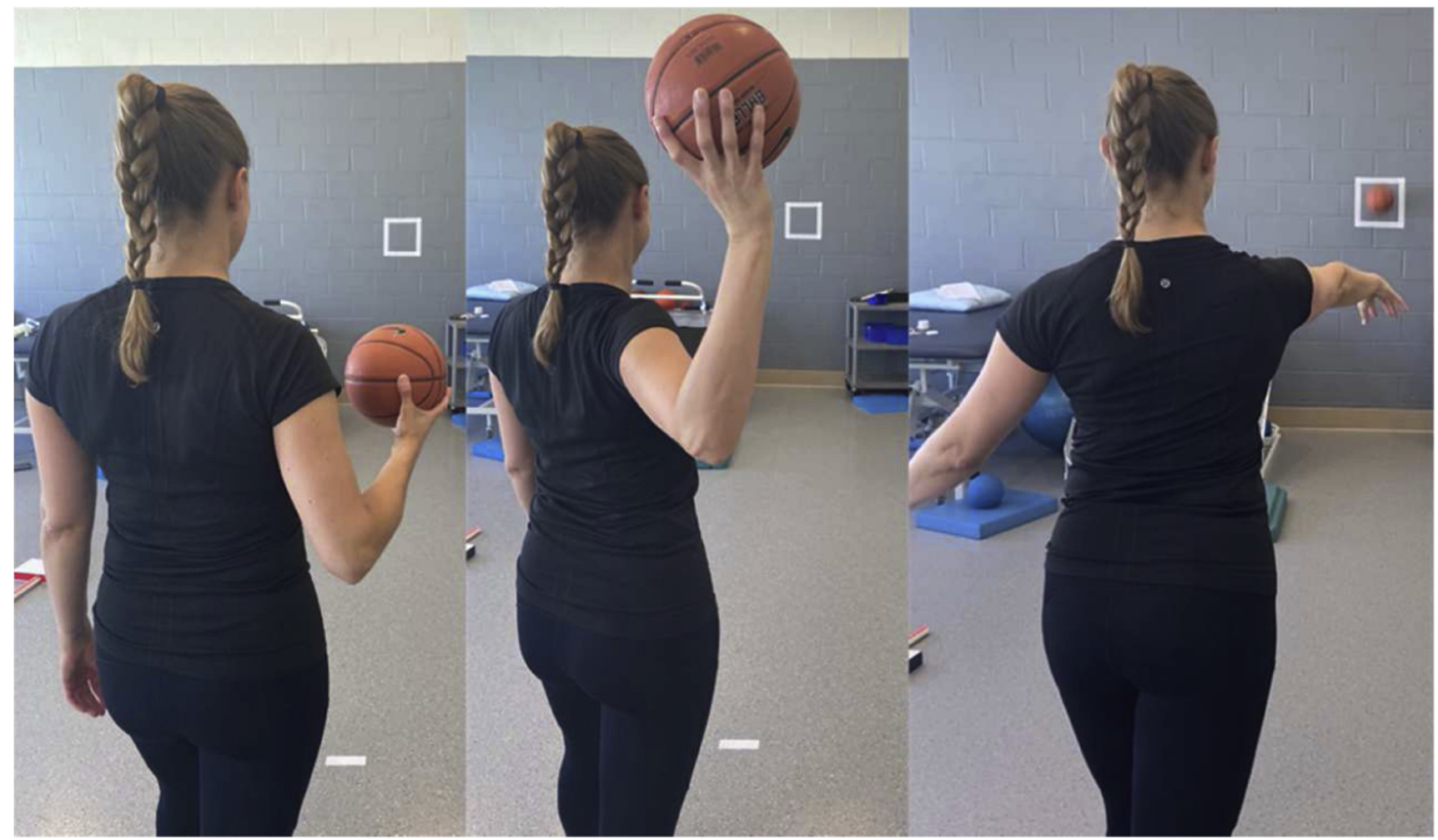

Fig 5. The Functional Throwing Performance Index measures the accuracy of overhand throwing athletes.

$60 \%$, whereas female athletes are typically $29 \%$ accurate with a range from $17 \%$ to $41 \%{ }^{32}$

\section{Materials}

- 21 " ball

- Tape (athletic or another easily visible tape)

\section{Testing Procedure}

- The athlete stands $15^{\prime}$ from the target

- $\mathrm{l}^{\prime} \times \mathrm{l}^{\prime}$ target is placed $4^{\prime}$ above floor

- $21^{\prime \prime}$ circumference ball

- Using a 21 " circumference ball, the athlete performs eight warmup throws starting at $25 \%$ submaximal effort working up to $100 \%$ maximal effort.

- The athlete then has 30 seconds to throw the ball at the target as many times as possible.

\section{Measurements}

- Record number of accurate throws as well as total throws.

- The throw is accurate as long as any part of the target is hit.

Formal interval sports program does exit return to throwing, return to softball throwing, return to tennis, and return to golf. ${ }^{33,34}$ Such programs assist in guiding the sports medicine clinician and athlete through a gradually progressed training routine that is sport-specific. It is advised that such sport-specific programs are commenced after an appropriate restoration of range of motion, muscle performance, proprioception, and successful performance on functional testing. Any time an athlete struggles with progressing to the next phase of the specific return to sport progression, they should consult with their sports medicine professional to re-assess status and adjust the rehabilitation plan accordingly.

For contact athletes such as American football players, wrestlers, or rugby players, it is recommended that an athlete be challenged and tested with functional activities that require pushing. One such functional test is The One Arm Hop Test, ${ }^{35}$ which measures strength, power, and stability in contact athletes (Fig 6). Qualitatively, this test can reveal core weakness, impaired scapular control, and pain with bodyweight loading and impact on the step during this sport-specific movement. Also, in uninjured players, the side-to-side difference was found to be minimal $(4.4 \%)$.

\section{Materials}

- 4" step

\section{Testing Procedure}

- The athlete assumes a one-arm pushup position: weight-bearing hand perpendicular to the floor, back flat, feet shoulder-width apart.

- Instruct the athlete to hop on and off a $4 "$ step literally 


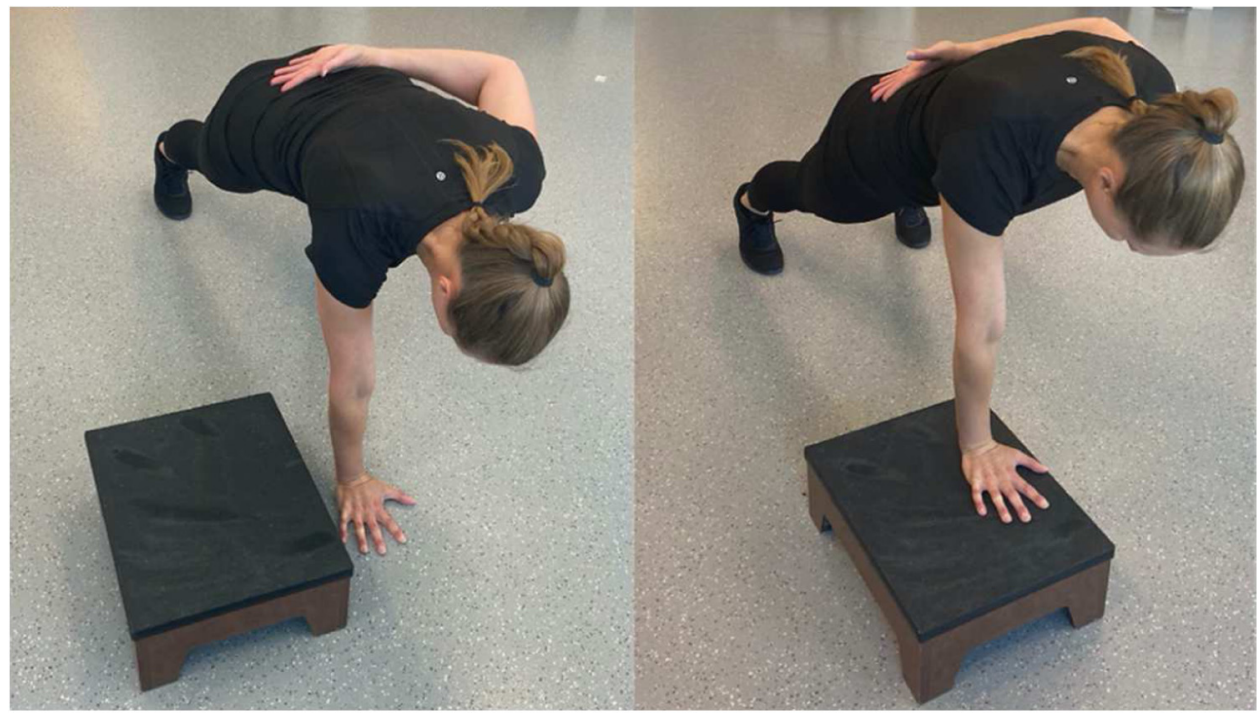

Fig 6. The One Arm Hop Test measures strength, power, and stability in contact athletes.

- The athlete hops five times as quickly as possible

\section{Measurements}

- The athlete must fully hop onto the step

- Knees may not touch down

- The back must remain reasonably flat

\section{Norms}

- Uninjured wrestlers: 2.95-7.07 seconds

- Uninjured football players: 3.20-9.95 seconds

Other functional tests to consider during the functional training and screening process for return to play are the Pushup Test and the Modified Pull-Up test, and the Athletic Shoulder Test.

\section{The Pushup Test}

The Pushup Test $^{36}$ requires the participant to perform as many pushups as quickly as possible for 15 seconds (Fig 7). A warmup 15-second submaximal trial is performed before completing 3 maximal trials with 45 seconds of rest in between each trial. An average number of pushups during the 3 trials is recorded. Male athletes perform this test in the standard pushup position, and female athletes perform this test in the modified position with both knees contacting the floor with feet off the ground.

\section{The Modified Pull-Up Test}

The Modified Pull-Up Test ${ }^{36}$ is performed using a secure adjustable height bar for gripping and pulling and a bench used to support the subject's feet or lower extremities. Participants are supine with heels on the bench while using an overhand grip on the bar. Male athletes perform this test with heels supported on the bench, and female athletes perform this test with their lower legs, just below the knees, supported on the bench. The participant should begin this test hanging from the bar with arms fully extended. Similar to the pushup test, trials are 15 seconds long with a submaximal warmup trial followed by 3 maximal trials with 45 seconds of rest in-between each trial. The average of 3 trials is their score. It has been reported that the ratio of pushup to modified pull-up is 1.57:1 in males and

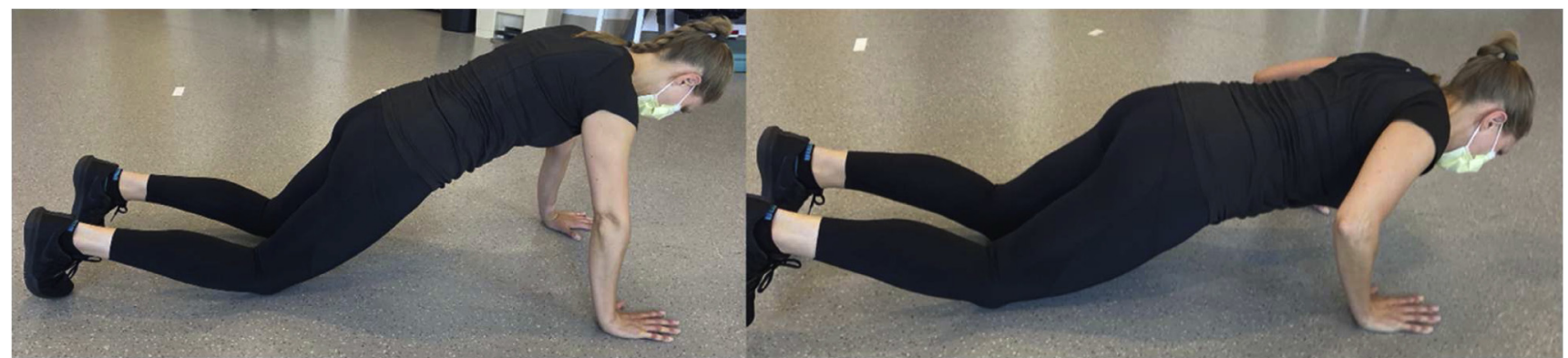

Fig 7. The Pushup Test measures muscular endurance of the upper body muscles. 
2.72:1 in female athletes. This implies it is much easier for both sexes to do more pushups than pull-ups in a given time frame. The aforementioned recommended functional tests are organized in a separate table for quick reference (Appendix Table 2, available at www. arthroscopyjournal.org).

\section{Athletic Shoulder Test}

The Athletic Shoulder Test ${ }^{37,38}$ is a relatively new and novel way of assessing shoulder strength to assist in guiding safe and asymptomatic return to tackling activity as part of a return-to-play assessment process, particularly in assessing the maintenance of shoulder stability. As studied in male ruby players, the test assesses isometric long-level shoulder muscle performance on a force platform in the prone position with the upper extremity in an I, Y, and T position. Further work with the Athletic Shoulder Test to establish normative data in both male and female athletes will assist the sports medicine clinician with an additional 1 tool in the sports assessment process.

\section{Further Exploration/Research}

A systematic review of the literature looking at various competitive sports, injuries, and potential male and female differences does warrant a more detailed look at a return-to-sport guidelines and training regiments (pre-, mid-, and postseason) to assist in better customizing and potentially injury reducing techniques between male and female athletes. Consistent areas derived from this commentary appear to need an increased focus on proper screening preseason for all athletes, identifying common injuries associated with specific competitive sports, and a better understanding the incidence of injury type with male and female athletes in each specific sport. A better understanding of these areas may assist coaches and medical professionals decrease injury incidence by customizing protocols to their specific sport and understanding strengths and weaknesses in both female and male athletes.

\section{Conclusions}

In summary, return to play of the female overhead athlete requires a multifactorial approach that should include awareness of the athlete's medical history, previous sports role(s), familiarity with the athlete's sport (typical injuries, biomechanical requirements, etc.), and their specific goals and expectations. Their stage of life, their sex, their position, and the sport they participate in should guide the return to sports plan. The clinician can then choose impairment measures and functional tests that best relate to the athlete's sport, such as weight-bearing, throwing, overhead stability/load, etc. Clearing an athlete for full participation should also include an assessment and screening of overall movement patterns as an impairment or altered movement pattern in the lower extremities could place an athlete at increased risk of upper-extremity injury.

\section{References}

1. Chimera NJ, Smith CA, Warren M. Injury history, sex, and performance on the functional movement screen and Y balance test. J Athl Train 2015;50:475-485.

2. Uhorchak JM, Scoville CR, Williams GN, Arciero RA, St Pierre P, Taylor DC. Risk factors associated with noncontact injury of the anterior cruciate ligament: A prospective four-year evaluation of 859 West Point cadets. Am J Sports Med 2003;31:831-842.

3. Balachandar V, Marciniak JL, Wall O, Balachandar C. Effects of the menstrual cycle on lower-limb biomechanics, neuromuscular control, and anterior cruciate ligament injury risk: A systematic review. Muscles Ligaments Tendons J 2017;7:136-146.

4. Herzberg SD, Motu'apuaka ML, Lambert W, Fu R, Brady J, Guise JM. The effect of menstrual cycle and contraceptives on ACL injuries and laxity: A Systematic review and meta-analysis. Orthop J Sports Med 2017;5: 2325967117718781.

5. Vafadar AK, Côté JN, Archambault PS. Sex differences in the shoulder joint position sense acuity: A cross-sectional study. BMC Musculoskelet Disord 2015;16:273.

6. Keen AD, Drinkwater BL. Irreversible bone loss in former amenorrheic athletes. Osteoporos Int 1997;7:311-315.

7. Logue DM, Madigan SM, Melin A, et al. Low energy availability in athletes 2020: An updated narrative review of prevalence, risk, within-day energy balance, knowledge, and impact on sports performance. Nutrients 2020;12(3).

8. Elliott-Sale KJ, Tenforde AS, Parziale AL, Holtzman B, Ackerman KE. Endocrine effects of relative energy deficiency in sport. Int J Sport Nutr Exerc Metab 2018;28: 335-349.

9. Brook EM, Tenforde AS, Broad EM, et al. Low energy availability, menstrual dysfunction, and impaired bone health: A survey of elite para athletes. Scand J Med Sci Sports 2019;29:678-685.

10. Melin AK, Heikura IA, Tenforde A, Mountjoy M. Energy availability in athletics: Health, performance, and physique. Int J Sport Nutr Exerc Metab 2019;29:152-164.

11. Kox LS, Kuijer PP, Kerkhoffs GM, Maas M, FringsDresen MH. Prevalence, incidence and risk factors for overuse injuries of the wrist in young athletes: A systematic review. Br J Sports Med 2015;49:1189-1196.

12. Thompson LV. Skeletal muscle adaptations with age, inactivity, and therapeutic exercise. J Orthop Sports Phys Ther 2002;32:44-57.

13. Thompson LV. Effects of age and training on skeletal muscle physiology and performance. Phys Ther 1994;74: 71-81.

14. Warren MP, Brooks-Gunn J, Fox RP, Holderness CC, Hyle EP, Hamilton WG. Osteopenia in exercise-associated amenorrhea using ballet dancers as a model: A longitudinal study. J Clin Endocrinol Metab 2002;87:3162-3168.

15. Hanson BE, Joyner MJ, Casey DP. Sex-related differences in rapid-onset vasodilation: Impact of aging. J Appl Physiol (1985) 2021;130:206-214. 
16. Anderson BE, Neumann ML, Huxel Bliven KC. Functional movement screen differences between male and female secondary school athletes. J Strength Cond Res 2015;29:1098-1106.

17. Borms D, Cools A. Upper-extremity functional performance tests: Reference values for overhead athletes. Int J Sports Med 2018;39:433-441.

18. Nelson CE, Rayan GM, Judd DI, Ding K, Stoner JA. Survey of hand and upper extremity injuries among rock climbers. Hand (N Y) 2017;12:389-394.

19. O'Connor S, Huseyin OR, Whyte EF, Lacey P. A 2-year prospective study of injuries and illness in an elite national junior tennis program. Phys Sportsmed 2020;48:342-348.

20. Butler R, Arms J, Reiman M, et al. Sex differences in dynamic closed kinetic chain upper quarter function in collegiate swimmers. J Athl Train 2014;49:442-446.

21. Shih YF, Wang YC. Spiking kinematics in volleyball players with shoulder pain. J Athl Train 2019;54:90-98.

22. Vincent HK, Zdziarski LA, Vincent KR. Review of lacrosserelated musculoskeletal injuries in high school and collegiate players. Sports Health 2015;7:448-451.

23. Myers NL, Sciascia AD, Kibler WB, Uhl TL. Volume-based interval training program for elite tennis players. Sports Health 2016;8:536-540.

24. Goldbeck TG, Davies GJ. Test-retest reliability of the closed kinetic chain upper extremity stability test: A clinical field test. J Sport Rehabil 2000;9:35-45.

25. Tucci HT, Martins J, Sposito Gde C, Camarini PM, de Oliveira AS. Closed Kinetic Chain Upper Extremity Stability test (CKCUES test): A reliability study in persons with and without shoulder impingement syndrome. BMC Musculoskelet Disord 2014;15:1.

26. Hegedus EJ, Vidt ME, Tarara DT. The best combination of physical performance and self-report measures to capture function in three patient groups. Phys Ther Rev 2014;19: 196-203.

27. Cramer J, Quintero M, Rhinehart A, et al. Exploration of score agreement on a modified Upper Quarter Y-Balance Test kit as compared to the Upper Quarter Y-Balance Test. Int J Sports Phys Ther 2017;12:117-124.
28. Westrick RB, Miller JM, Carow SD, Gerber JP. Exploration of the y-balance test for assessment of upper quarter closed kinetic chain performance. Int J Sports Phys Ther 2012;7:139-147.

29. Gorman PP, Butler RJ, Plisky PJ, Kiesel KB. Upper Quarter Y Balance Test: Reliability and performance comparison between genders in active adults. J Strength Cond Res 2012;26:3043-3048.

30. Chmielewski TL, Martin C, Lentz TA, et al. Normalization considerations for using the unilateral seated shot put test in rehabilitation. J Orthop Sports Phys Ther 2014;44: 518-524.

31. Harris C, Wattles AP, DeBeliso M, Sevene-Adams PG, Berning JM, Adams KJ. The seated medicine ball throw as a test of upper body power in older adults. J Strength Cond Res $2011 ; 25: 2344-2348$.

32. Davies GJ, Dickoff-Hoffman S. Neuromuscular testing and rehabilitation of the shoulder complex. J Orthop Sports Phys Ther 1993;18:449-458.

33. Reinold MM, Wilk KE, Reed J, Crenshaw K, Andrews JR. Interval sport programs: Guidelines for baseball, tennis, and golf. J Orthop Sports Phys Ther 2002;32:293-298.

34. Axe MJ, Windley TC, Snyder-Mackler L. Data-based interval throwing programs for collegiate softball players. J Athl Train 2002;37:194-203.

35. Falsone SA, Gross MT, Guskiewicz KM, Schneider RA. One-arm hop test: Reliability and effects of arm dominance. J Orthop Sports Phys Ther 2002;32:98103.

36. Negrete RJ, Hanney WJ, Pabian P, Kolber MJ. Upper body push and pull strength ratio in recreationally active adults. Int J Sports Phys Ther 2013;8:138-144.

37. Morrison G, Ashworth B, Taylor-Kaveney T. The validity of the sphygmomanometer for shoulder strength assessment in amateur rugby union players. Phys Ther Sport 2021;47:59-65.

38. Ashworth B, Hogben P, Singh N, Tulloch L, Cohen DD. The Athletic Shoulder (ASH) test: Reliability of a novel upper body isometric strength test in elite rugby players. BMJ Open Sport Exerc Med 2018;4:e000365. 
Appendix Table 1. Functional Movement System (FMS) Scoring Criterion With Seven Test Activities

\begin{tabular}{lcc}
\hline \multicolumn{1}{c}{ Test } & Laterality & Raw Score \\
\hline Deep squat (Fig 1A) & $\mathrm{L}$ \\
In-line lunge (Fig 1B) & $\mathrm{R}$ \\
& $\mathrm{L}$ \\
Hurdle step (Fig 1C) & $\mathrm{R}$ \\
Shoulder mobility (Fig 1D) & $\mathrm{L}$ \\
& $\mathrm{R}$ \\
Active straight-leg raise (Fig 1E) & $\mathrm{L}$ \\
Trunk stability pushup (Fig 1F) & $\mathrm{R}$ \\
& $\mathrm{L}$ \\
Rotary stability (Fig 1G) & $\mathrm{R}$ \\
& $\mathrm{L}$ \\
& $\mathrm{R}$ \\
\hline
\end{tabular}

\footnotetext{
Score criteria: 4-point ordinal scale; 0-21 points

0 : Pain, regardless of performance

1: Unable to perform

2: Perform with compensation

3: Perform as directed

*Score of 14 demonstrates a reduced risk of injury with physical activity.

** Score of 13 or less may be indicative of increased risk of injury with physical activity.
} 


\begin{tabular}{|c|c|c|c|c|}
\hline & & & & \\
\hline $\begin{array}{l}\text { Closed Kinetic Chain Upper } \\
\text { Extremity Stability Test }{ }^{19}\end{array}$ & $\begin{array}{l}\text { - Tape (athletic or another easily } \\
\text { visible tape) } \\
\text { - Clock or timer }\end{array}$ & $\begin{array}{l}\text { - Place } 2 \text { strips of tape parallel to } \\
\text { each other } 36 \text { inches apart on } \\
\text { the floor. However, when } \\
\text { completing this test with } \\
\text { female athletes, a } 36 \text {-inch- } \\
\text { wide may not be reasonable } \\
\text { given the size of the female } \\
\text { athlete. Narrowing this } \\
\text { distance to fit one's body } \\
\text { composition is suggested. } \\
\text { - Starting position is one hand on } \\
\text { each piece of tape in a pushup } \\
\text { position or a modified pushup } \\
\text { position with knees and toes on } \\
\text { the floor. } \\
\text { The athlete will then rapidly } \\
\text { touch the opposite hand or } \\
\text { touch tape under the opposite } \\
\text { hand. } \\
\text { - After touching, the hand is } \\
\text { returned to its original starting } \\
\text { position. The athlete then } \\
\text { performs the same movement } \\
\text { with the opposite hand. } \\
\text { - The total time for the trial is } 15 \\
\text { s. Record total number of } \\
\text { touches completed in } 15 \mathrm{~s} \text {. } \\
\text { - The athlete performs a warmup } \\
\text { trial and then } 3 \text { test trials with a } \\
\text { rest period of } 45 \mathrm{~s} \text { between } \\
\text { trials. An average of } 3 \text { trials is } \\
\text { used for test score. } \\
\text { - Female athletes are scored } \\
\text { based on a modified pushup } \\
\text { position }\end{array}$ & $\begin{array}{l}\text { - Touches are counted each time } \\
\text { the hand touches the opposing } \\
\text { hand or tape } \\
\text { - Power score can be calculated } \\
\text { by: (average \# of touches } \times \\
68 \% \text { of body weight in } \mathrm{kg} \text { ) } / 15 \mathrm{~s}\end{array}$ & $\begin{array}{l}\text { Measures speed, agility, and/or } \\
\text { power but requires upper- } \\
\text { quarter stability to perform } \\
\text { without symptoms. }\end{array}$ \\
\hline
\end{tabular}


Seated Medicine

Ball Throw Test ${ }^{25}$

Functional Throwing Performance Index ${ }^{27}$
- 6-lb medicine ball

- Tape (athletic or another easily visible tape

\section{- $21^{\prime \prime}$ ball}

- Tape (athletic or another easily visible tape)
Procedure

Measurements

Measures

The athlete sits back against

wall, next to a doorway, to allow the test arm to move

freely without touching the

wall. Legs are bent with feet flat on the floor.

- Place 2 parallel strips of tape $36 "$ apart on the floor before the athlete forms a track to guide the throws.

- The athlete holds a 6-lb

medicine ball at shoulder height on the test side.

- The athlete is instructed to push (rather than throw) the ball as far forward as possible while:

o Keeping head, back, and contralateral shoulder

blade in contact with the wall.

o Keeping contralateral arm relaxed in the lap

- Encourage to facilitate the maximal effort.

- The athlete performs 2 practice trials: one at $75 \%$ of maximal effort and one at $100 \%$

maximal effort. 20-30 seconds of rest between each trial.

- Perform 3 maximal effort trials.

- The athlete stands 15' from the target

- $l^{\prime} \times 1^{\prime}$ target is placed $4^{\prime}$ above floor

- 21" circumference ball

- Using a 21 " circumference ball the athlete performs 8 warmup throws starting at $25 \%$

submaximal effort working up

to $100 \%$ maximal effort

- The athlete then has 30 seconds to throw the ball at the target as many times as possible.
- Record distance from the wall to the point where the ball first contacted the floor in

- Calculate the average distance from 3 maximal effort trials.
Measures unilateral upper extremity power.

\section{Measures the accuracy of}

overhand throwing athletes. 


\begin{tabular}{|c|c|c|c|c|}
\hline Test & Materials & Procedure & Measurements & Measures \\
\hline The One Arm Hop Test ${ }^{30}$ & $4^{\prime \prime}$ step & $\begin{array}{l}\text { - The athlete assumes a one-arm } \\
\text { pushup position: weight- } \\
\text { bearing hand perpendicular to } \\
\text { the floor, back flat, feet } \\
\text { shoulder-width apart. } \\
\text { - Instruct the athlete to hop on } \\
\text { and off a } 4 \text { " step literally } \\
\text { - The athlete hops } 5 \text { times as } \\
\text { quickly as possible }\end{array}$ & $\begin{array}{l}\text { - The athlete must fully hop onto } \\
\text { the step } \\
\text { - Knees may not touch down } \\
\text { - The back must remain } \\
\text { reasonably flat }\end{array}$ & $\begin{array}{l}\text { Measures strength, power, and } \\
\text { stability in contact athletes. } \\
\text { Need to be careful in athletes } \\
\text { with posterior shoulder } \\
\text { instability. }\end{array}$ \\
\hline 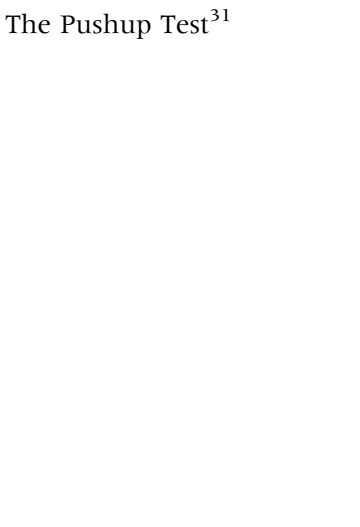 & None & $\begin{array}{l}\text { - Athlete performs as many } \\
\text { pushups as quickly as possible } \\
\text { for } 15 \mathrm{~s} \text {. } \\
\text { - A warmup } 15 \text {-ssubmaximal } \\
\text { trial is performed before } \\
\text { completing } 3 \text { maximal trials } \\
\text { with } 45 \mathrm{~s} \text { of rest in between } \\
\text { each trial. } \\
\text { - Male athletes perform this test } \\
\text { in the standard pushup } \\
\text { position. } \\
\text { - Female athletes perform this } \\
\text { test in the modified position } \\
\text { with both knees contacting the } \\
\text { floor with feet off the ground }\end{array}$ & $\begin{array}{l}\text { An average number of pushups } \\
\text { during the } 3 \text { trials is recorded. }\end{array}$ & $\begin{array}{l}\text { Assesses overall upper-extremity } \\
\text { strength. }\end{array}$ \\
\hline The Modified Pull-Up Test ${ }^{31}$ & $\begin{array}{l}\text { Using a secure adjustable height } \\
\text { bar for gripping and pulling and } \\
\text { a bench used to support the } \\
\text { subject's feet or lower } \\
\text { extremities. }\end{array}$ & $\begin{array}{l}\text { - Athletes are supine with heels } \\
\text { on the bench while using an } \\
\text { overhand grip on the bar. } \\
\text { - Male athletes perform this test } \\
\text { with heels supported on the } \\
\text { bench. } \\
\text { - Female athletes perform this } \\
\text { test with their lower legs, just } \\
\text { below the knees, supported on } \\
\text { the bench } \\
\text { - The athlete should begin this } \\
\text { test hanging from the bar with } \\
\text { arms fully extended. Similar to } \\
\text { the pushup test, trials are } 15 \\
\text { seconds long with a } \\
\text { submaximal warmup trial } \\
\text { followed by } 3 \text { maximal trials } \\
\text { with } 45 \text { seconds of rest in- } \\
\text { between each trial. }\end{array}$ & $\begin{array}{l}\text { - The average of } 3 \text { trials is their } \\
\text { score. } \\
\text { - It has been reported that the } \\
\text { ratio of pushup to modified } \\
\text { pull-up is } 1.57: 1 \text { in males and } \\
2.72: 1 \text { in females. This implies } \\
\text { it is much easier for both sexes } \\
\text { to do more pushups than pull- } \\
\text { ups in a given time frame. }\end{array}$ & $\begin{array}{l}\text { Assesses overall upper-extremity } \\
\text { strength. }\end{array}$ \\
\hline
\end{tabular}

